\title{
Traffic Flow Assignment by Using Road Impedance Function Based on Subjective Preference
}

\author{
Changcheng $\mathrm{Li}^{1,2}$ \\ Research Institute of Highway, Ministry of Transport ${ }^{1}$ \\ Key Laboratory of Road Safety Technologies, Ministry of Transport ${ }^{2}$ \\ No.8, Xitucheng Rd., Haidian Dist., Beijing, China, 100088 \\ E-mail: cc.li@rioh.cn
}

\begin{abstract}
Research on road impedance function is limited to directly using travel time or travel cost as road impedance value, and the influence of distance, travel cost and level of service on route choice behaviors are not considered comprehensively. Therefore, this paper proposes a construction method for road impedance function based on subjective wishes or preference, which is a function of average link travel time or average speed and distance. This paper collects the initial data through the questionnaire and gets parameters by statistic regression analysis. On this basis, we take the Beijing-Hong Kong-Macao freeway network in Hubei Province as an example to allocate the traffic flow, and verify the applicability of the new traffic impedance function of traffic assignment.
\end{abstract}

Keywords-Road impedance function; calibration; subjective preference; traffic flow distribution; passenger car

\section{INTRODUCTION}

Traffic assignment according to the current and the future predict traffic demand and traffic flow conditions is the foundation to carry out road network guidance and traffic control measurements. The construction of traffic impedance function and the definition of traffic impedance, as key factors to road network traffic assignment, are crucial to definite the equilibrium traffic around the road network, improve road level of overall service and reduce delays caused by traffic congestion.

The BPR impedance function model proposed by Bureau of Public Road (renamed to FHWA) is representative among the study of impedance function[1-2]. Based on the preceding research results, Shoufeng Ma[3] considered the influence of the maximum volumes of traffic and points out that the arrival time constraints can be considered as both arrival time constraints and traffic control constraints to establish a dynamic traffic flow assignment model with a limit of deadline under congestion. A genetic algorithm is proposed for solving the model in discrete-time version offering a solution to the model after discretization. Based on the user equilibrium traffic assignment with utility theory, Xinxin Wei[4] assumed that the link time is variable, then used the Morgenstern utility function to describe users decisions, and finally build a new equilibrium principle and assignment model. Wenjing Wang[5] use Matlab to allocate traffic flow and emulate the traffic net work for the research purpose of the effect to results of flow to be allocated, the number of flow distribution, and Logit model parameters on the distribution of the results. Wang Yuanqing[6] take into account the effect of time, toll, traffic flow, the effect of tollbooth and city node as a whole, proposed a comprehensive model of impedance function via parameter calibration which solves the time parameter calibration problem. This paper converts the general traffic impedance model into internal function of Trans CAD through formula transformation. Yingying Zhang[7] put service level in the impedance function as a variable by analyzing several factors such as trip time, trip fare and service level, Pair wise comparison method, expert judgment method and AHP method are used to quantify the service level and modified the traffic impedance function model. Weixiong Zha[8] considered influencing factors of traffic flows under different road conditions but without considering the existence of toll stations. On this basis, the delay of unsaturated traffic at approach of intersection was analyzed, the node impedance function of unsaturated urban mixed traffic was built and the parameters were calibrated by using maximum likelihood calibration method. Nan $\mathrm{He}$ [9] considered the speed limit, the number of lanes, density of traffic lights sites, density of bus station sites, saturation and other effect factors of traffic congestion and road impedance function, on the basis of which the classic BPR function was improved .

Above all, many researchers have done a lot of work on the aspect of parameter calibration method and factors affecting traffic impedance based on BPR function, travel time and travel cost were often used as a impedance coefficient. This method, though simple, easy to operate, does not take some factors into account, such as distance, cost, service level of traveler route, which could affect travelers' behavior, in another words, ignoring people's subjective attitude on route choice. In this paper, a construction method of traffic impedance function based on travelers' subjective preference was proposed, as a solution to the problem that there is absent consideration of current traffic impedance function and it is difficult to reflect the traveler preference. The theory and method was proposed for traffic guidance under unfavorable condition based on new impedance function traffic allocating method. 


\section{STUDY ON THE TRAFFIC IMPEDANCE FUNCTION}

\section{A. Description of the road impedance function}

Highway road resistance consists of road impedance, node impedance, while the latter can be ignored for its small value compared with the former. So road impedance accounts for most highway traffic impedance.

Road impedance is used to describe the resistance of vehicle in the process of driving along the road, reflects degree of road smooth. It is the key to traffic assignment, also is the prediction of traffic assignment. The accuracy of the impedance function and its parameters calibration directly affect the route choice of network. Impedance function has a variety of forms, generally defined by distance, time, speed, cost, or a weighted average of these factors above. Running time is most commonly used to describe road impedance among them, which can directly reflect the resistance degree in the process of driving.

B. Traffic impedance function based on traveler's subjective preference

In general, the value of road impedance is measured by travel time. But in addition to the travel time, it is affected by many factors which can change people's subjective preference, such as travel cost, trip distance, and highway service level [10]. Therefore, road impedance function should include vehicle travel time and time cost of these factors. Based on the above analysis, a new highway impedance function is proposed in this study as follows:

$$
\begin{gathered}
C_{\mathrm{ij}}=t_{\mathrm{ij}}+M \\
M=M_{\text {travel cost }}+M_{\text {trip distance }}+M_{\text {service level }}
\end{gathered}
$$

Where, $C_{i j}$ is traffic impedance in section between node $\mathrm{i}$ and $\mathrm{j} ; \mathrm{t}_{i j}$ is travel time in section between node $\mathrm{i}$ and $\mathrm{j}$; $M$ is time cost that the factors is transformed into. $M_{\text {travel cost }}, M_{\text {trip distance }}, M_{\text {service level }}$ are time cost converted from highway tolls, travel distance and service level.

On the highway the drivers of the vehicle are affected by subjective factors, such as distance, the sensitivity to charges and so on. We collected the public's opinions through a questionnaire because it is difficult to quantitatively analysis these factors, as shown in Table 1. In order to simplify processing, we set that the highway charge fee is 0.5 yuan per kilometer.

\begin{tabular}{|c|}
\hline Travelers' route choice questionnaire \\
\hline Gender: $\square$ male $\square$ female \\
\hline 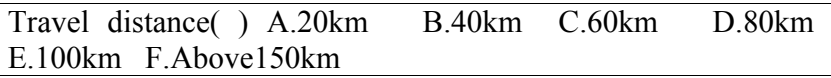 \\
\hline $\begin{array}{l}\text { Trip purpose( ) A. officials travel } \quad \text { B. Logistics } \\
\text { C. Visiting } \\
\text { friends D. Tourism and entertainment }\end{array}$ \\
\hline $\begin{array}{l}\text { Vehicle type ( ) A. Passenger car } \quad \text { B. Operating vehicles } \\
\text { C. Ordinary goods truck D. Operations / Logistics truck }\end{array}$ \\
\hline $\begin{array}{l}\text { Your choice in general ( ) A. Expressways of Beijing- } \\
\text { Hongkong-Macao B. National Highway G107 }\end{array}$ \\
\hline $\begin{array}{l}\text { The reasons for the choice of Expressways of Beijing- } \\
\text { Hongkong-Macao ( ) (Multiselect) } \\
\text { conditions of national highway } \\
\text { C. Fast B. Poor road } \\
\end{array}$ \\
\hline
\end{tabular}

TABLE I. TRAVELERS' ROUTE CHOICE QUESTIONNAIRE

\begin{tabular}{|l|}
\hline \multicolumn{2}{|c|}{ Travelers' route choice questionnaire } \\
\hline vulnerable to penalties D. To save time \\
\hline The reasons for the choice of National Highway G107 ( ) \\
(Multiselect) A. Short distance, good accessibility B. Without \\
toll C. Suitable speed Good scenery along the way \\
\hline If the vehicle speed is within $40 \mathrm{~km} / \mathrm{h}$ in National Highway \\
G107, you would choose to give up the Expressways of \\
Beijing-Hongkong-Macao when traveling speed is less than ( )? \\
A.90 km/h B. $80 \mathrm{~km} / \mathrm{h} \quad$ C. $70 \mathrm{~km} / \mathrm{h} \quad$ D. $60 \mathrm{~km} / \mathrm{h}$ E. $50 \mathrm{~km} / \mathrm{h}$ \\
\hline
\end{tabular}

Since different types of cars and travel are involved in the survey questionnaires, this analysis is only for Minibus and trip purpose for individual behavior, such as visiting friends and tourism and entertainment. By analyzing the questionnaires, summary data results of minibus are in Table 2.

TABLE II. TRAVELERS' ROUTE CHOICE OF MINIBUS

\begin{tabular}{|c|c|c|c|}
\hline $\begin{array}{c}\text { distance } \\
(\mathbf{k m})\end{array}$ & Cost(yuan) & $\begin{array}{c}\text { Speed in } \\
\text { National } \\
\text { Highway (km/h) }\end{array}$ & $\begin{array}{c}\text { The critical } \\
\text { speed (km/h) }\end{array}$ \\
\hline 20 & 10 & 40 & 90 \\
\hline 40 & 20 & 40 & 80 \\
\hline 60 & 30 & 40 & 70 \\
\hline 80 & 40 & 40 & 60 \\
\hline 100 & 50 & 40 & 50 \\
\hline
\end{tabular}

Where, the average speed in national highway is $40 \mathrm{~km} / \mathrm{h}$; the critical speed is running speed of the vehicle on expressway when the traffic impedance of expressway is equal to that of national highway.

If the travel time of vehicle on expressway is same to that on national highway, some factors are considered to change travelers' subjective preference, which also affect the traffic impedance of expressway. The factors include trip distance, travel cost, and highway service level. Among them, highway service level is expressed by using the error between the actual speed of vehicle on national highway and the actual speed of vehicle on freeway.

Therefore, traffic impedance of expressway can be expressed by following formula.

$$
C_{\mathrm{ij}}=t_{\mathrm{ij}}+M=\frac{\mathrm{x}_{1}}{v_{E}} * 60+f\left(x_{1}, x_{2}, x_{3}\right)
$$

From (3), $v_{E}$ is actual speed of the vehicle on freeway; $\mathrm{X}_{1}$ is trip distance; $x_{2}$ is travel cost; $x_{3}$ is error between the speed of vehicle on national highway and the speed of vehicle on freeway.

It is therefore possible to formulate the running time of the vehicle on national highway as follows

$$
T_{\mathrm{ij}}=\frac{\mathrm{x}_{1}}{v_{R}} * 60
$$

Where, $T_{\mathrm{ij}}$ is running time of the vehicle on national highway; $v_{R}$ is speed of the vehicle on national highway, typically, $v_{R}=40 \mathrm{~km} / \mathrm{h}$. When the traffic impedance of expressway is equal to that of national highway, there is: 


$$
\frac{\mathrm{x}_{1}}{v_{R}} * 60=\frac{\mathrm{x}_{1}}{v_{E}} * 60+f\left(x_{1}, x_{2}, x_{3}\right)
$$

After the transformation:

$$
\left(\frac{x_{1}}{v_{R}}-\frac{x_{1}}{v_{E}}\right) * 60=f\left(x_{1}, x_{2}, x_{3}\right)
$$

Assuming that $\left(\frac{\mathrm{X}_{1}}{v_{R}}-\frac{\mathrm{X}_{1}}{v_{E}}\right) * 60=\Delta \mathrm{t}$ and there is a linear relationship between $\Delta \mathrm{t}$ and $x_{1}, x_{2}, x_{3}$, (7) is obtained.

$$
\Delta \mathrm{t}=\alpha x_{1}+\beta x_{2}+\gamma x_{3}
$$

In which, $\alpha, \beta, \gamma$ can be declared as parameters, and $x_{2}=0.5 x_{1}$. We will get:

$$
\Delta \mathrm{t}=\alpha x_{1}+0.5 \beta x_{1}+\gamma x_{3}=(\alpha+0.5 \beta) x_{1}+\gamma x_{3}=\theta x_{1}+\gamma x_{3}
$$

Using the method of linear regression, we can get parameters $\theta=0.350, \gamma=0.335$ with the data in the Table 3. So the specific expression of (8) is shown as follows:

$$
\Delta \mathrm{t}=0.350 x_{1}+0.335 x_{3}\left(R^{2}=0.959\right)
$$

The highway traffic impedance can be achieved by (10) combining (1) and (2).

$$
C_{\mathrm{ij}}=\frac{60 \mathrm{x}_{1}}{v_{E}}+0.350 x_{1}+0.335 x_{3}
$$

As $\mathrm{X}_{3}=\mathrm{v}_{E}-\mathrm{v}_{\mathrm{R}}$, by setting $\mathrm{v}_{\mathrm{R}}=40 \mathrm{~km} / \mathrm{h},(10)$ can be expressed as (11).

$$
C_{\mathrm{ij}}=\frac{60 \mathrm{x}_{1}}{\mathrm{v}_{E}}+0.350 \mathrm{x}_{1}+0.335 \mathrm{v}_{E}-13.4
$$

According to the relationship among time, speed and distance as $\mathrm{v}_{E}=60 L_{i j} / t_{i j}$, the highway traffic impedance can be calculated by (12).

$$
C_{\mathrm{ij}}=t_{\mathrm{ij}}+\frac{20.1 L_{i j}}{t_{\mathrm{ij}}}+0.350 L_{i j}-13.4
$$

Where, $L_{\mathrm{ij}}$ is the distance between node $\mathrm{i}$ and node $\mathrm{j}$.

TABLE III. VARIABLE VALUATIONS USED FOR IMPEDANCE FUNCTION PARAMETERS REGRESSION

\begin{tabular}{|c|c|c|c|}
\hline$\Delta \mathrm{t} / \mathbf{m i n}$ & $\begin{array}{c}\text { Travel distance/ } \\
X_{1}\end{array}$ & Cost $/ X_{2}$ & $\begin{array}{c}\text { Speed difference } \\
/ X_{3}\end{array}$ \\
\hline 16.7 & 20 & 10 & 50 \\
\hline 30.0 & 40 & 20 & 40 \\
\hline 38.6 & 60 & 30 & 30 \\
\hline 40.0 & 80 & 40 & 20 \\
\hline 30.0 & 100 & 50 & 10 \\
\hline
\end{tabular}

III. THE EXAMPLE ANALYSIS OF TRAFFIC FLOW ASSIGNMENT BASED ON TRAFFIC IMPEDANCE FUNCTION OF THE SUBJECTIVE PREFERENCE

Traffic flow assignment is to assign the predicted OD traffic flow to the road network according to the known description of the road network and certain rules, so that traffic flow of various road sections can be calculated and the traffic network working condition can also be analyzed and evaluated.

The method proposed was tested on the Xianning South-Quankou-Chibi-Xindian sections of Beijing-Hong Kong-Macao Expressway. This way is basically parallel with the G107 Road that there are a number of path choices from Xianning South to Xindian. As shown in Fig .1, this section of the road network has 4 exchange nodes, and set the Xianning South as Exchange 1, Quankou Exchange 2, Chibi Exchange 3, and Xindian Exchange 4.There are 8 paths from Xianning South to Xindian, which are a1-a2-a3, a1-a2-b3, a1-b2-a3, a1-b2-b3, b1-a2-a3, b1-a2-b3, b1-b2-a3, and b1-b2-b3.

In this case, the road impedance can be considered as a constant in every prediction interval (e.g. 15 minutes). Considering factors of multi route choice and resistance, the multi route traffic flow assignment method with a fixed impedance is selected in this test.

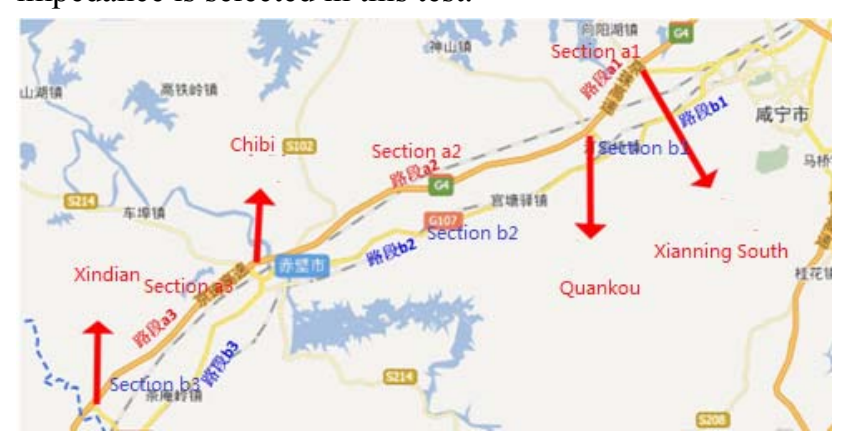

Figure 1. Network topology diagram from Xinning South to Xindian

The travel time of expressway sections a1, a2, a3 in the next 15 minutes are shown in Table 4.

TABLE IV. PREDICTED TRAVEL TIME OF EXPRESSWAy SECTIONS A1, $\mathrm{A} 2, \mathrm{~A} 3$

\begin{tabular}{|c|c|c|c|c|}
\hline $\begin{array}{c}\text { Road } \\
\text { Section }\end{array}$ & $\begin{array}{c}\text { Distance } \\
\text { (km) }\end{array}$ & $\begin{array}{c}\text { Index } \\
\text { Smoothing } \\
\text { (min) }\end{array}$ & $\begin{array}{c}\text { Neural } \\
\text { Network } \\
\text { (min) }\end{array}$ & $\begin{array}{c}\text { Comprehensive } \\
\text { value (min) }\end{array}$ \\
\hline $\begin{array}{c}\text { Xianning } \\
\text { South- } \\
\text { Quankou } \\
\text { (a1) }\end{array}$ & 7.07 & 6.1 & 5.4 & 5.2 \\
\hline $\begin{array}{c}\text { Quankou- } \\
\text { Chibi(a2) }\end{array}$ & 31.93 & 27.5 & 24.2 & 23.4 \\
\hline $\begin{array}{c}\text { Chibi- } \\
\text { Xindian(a } \\
\text { 3) }\end{array}$ & 18.42 & 15.9 & 14.0 & 13.5 \\
\hline
\end{tabular}

The traffic impedance between Xianning South and Quankou can be calculated by (12).

$$
C_{12}=t_{12}+\frac{20.1 L_{12}}{t_{12}}+0.350 L_{12}-13.4
$$




$$
=5.2+\frac{20.1 * 7.07}{5.2}+0.350 * 7.07-13.4=21.6
$$

In the same way, the traffic impedance between Quankou and Chibi and the traffic impedance between Chibi and Xindian can be achieved, which are as follows.

$$
C_{23}=48.6, C_{34}=34.0
$$

Since different kinds of vehicle are mixed seriously and the running situation is more complex on the national road than the expressway, an experienced speed value is given when forecasting the road vehicle travel time. Then, travel time is calculated according to the section length.

Due to the bad weather conditions, the vehicle speed is set at $40 \mathrm{~km} / \mathrm{h}$ and travel time of Quankou-Chibi and ChibiXindian are achieved which are shown in Table 5.

Road section selections between exchanges of the expressway and national road are implemented through selecting connecting lines and ramps. As a result, when calculating the traffic impedance, it is necessary to take the travel time of connecting lines and ramps into account.

If the traveler starts at the Xianning South exchange of G107, ends at the Xindian exchange, and the vehicle speed is set at $40 \mathrm{~km} / \mathrm{h}$, related connecting lines and ramps and travel time between the two exchanges are shown in Table 6.

The parameters in Table 5, Table 6 and the impedance of highway section a1, a2, a3 are used to calculate the traffic impedance between Xian-ning South to Xin-dian where there are 8 path, as shown in Table 7.

TABLE V. TRAVEL TIME OF SECTION B1, B2, B3

\begin{tabular}{|c|c|c|c|}
\hline Road Section & Distance(km) & Speed(km/h) & $\begin{array}{c}\text { Travel } \\
\text { Time(min) }\end{array}$ \\
\hline $\begin{array}{c}\text { Xianning South } \\
\text {-Quankou (b1) }\end{array}$ & 13 & 40 & 19.5 \\
\hline $\begin{array}{c}\text { Quankou-Chibi } \\
\text { (b2) }\end{array}$ & 33 & 40 & 49.5 \\
\hline $\begin{array}{c}\text { Chibi-Xindian } \\
\text { (b3) }\end{array}$ & 19 & 40 & 28.5 \\
\hline
\end{tabular}

TABLE VI. CONNECTING LINE AND RAMPS BETWEEN THE EXPRESSWAY AND NATIONAL HIGHWAY AND TRAVEL TIME

\begin{tabular}{|c|c|c|}
\hline Topological relations and meaning & Distance(km) & $\begin{array}{c}\text { Travel } \\
\text { Time(min) }\end{array}$ \\
\hline $\begin{array}{c}\text { b1-a1:Distance between the start of } \\
\text { the national road and the expressway } \\
\text { section a1 }\end{array}$ & 7.5 & 11.3 \\
\hline $\begin{array}{c}\text { a1-b2:Distance between the } \\
\text { expressway section a1 and the } \\
\text { national road section b2 }\end{array}$ & 3.3 & 5.0 \\
\hline $\begin{array}{c}\text { a2-b3:Distance between the } \\
\text { expressway section a2 and the } \\
\text { national road section b3 }\end{array}$ & 2.5 & 3.8 \\
\hline $\begin{array}{c}\text { b1-a2:Distance between the national } \\
\text { road section b1 and the expressway } \\
\text { section a2 }\end{array}$ & 3.3 & 5.0 \\
\hline $\begin{array}{c}\text { b2-a3:Distance between the national } \\
\text { road section b2 and the expressway } \\
\text { section a3 }\end{array}$ & 3.1 & 8.7 \\
\hline $\begin{array}{c}\text { a3-b3:Distance between the } \\
\text { expressway section a3 and the end of } \\
\text { the national road section b3 }\end{array}$ & 5.6 & 8.4 \\
\hline
\end{tabular}


Among them, $\mathrm{x}_{\mathrm{a}}$ is the path traffic volume; $\delta_{k}^{r s}$ is the variable of path, that is variable $0-1$, if road belong to the pathway K of road OD, then $\delta_{k}^{r s}=1$, or else $\delta_{k}^{r s}=0$.

The traffic volume of path al is:

$$
\mathrm{x}_{\mathrm{a} 1}=\mathrm{f}_{1}^{r s}+\mathrm{f}_{2}^{r s}+\mathrm{f}_{3}^{r s}+\mathrm{f}_{4}^{r s}=470(\mathrm{pcu})
$$

The traffic volume of path a2 is:

$$
\mathrm{X}_{\mathrm{a} 2}=\mathrm{f}_{1}^{r s}+\mathrm{f}_{2}^{r s}+\mathrm{f}_{5}^{r s}+\mathrm{f}_{6}^{r s}=500(\mathrm{pcu})
$$

The traffic volume of path a3 is:

$$
\mathrm{X}_{\mathrm{a} 3}=\mathrm{f}_{1}^{r s}+\mathrm{f}_{3}^{r s}+\mathrm{f}_{5}^{r s}+\mathrm{f}_{7}^{r s}=471(\mathrm{pcu})
$$

The traffic volume of path $\mathrm{b} 1$ is:

$$
\mathrm{X}_{\mathrm{b} 1}=\mathrm{f}_{5}^{r s}+\mathrm{f}_{6}^{r s}+\mathrm{f}_{7}^{r s}+\mathrm{f}_{8}^{r s}=530(\mathrm{pcu})
$$

The traffic volume of path $\mathrm{b} 2$ is:

$$
\mathrm{X}_{\mathrm{b} 2}=\mathrm{f}_{3}^{r s}+\mathrm{f}_{4}^{r s}+\mathrm{f}_{7}^{r s}+\mathrm{f}_{8}^{r s}=500(\mathrm{pcu})
$$

The traffic volume of path $\mathrm{b} 3$ is:

$$
\mathrm{x}_{\mathrm{b} 3}=\mathrm{f}_{2}^{r s}+\mathrm{f}_{4}^{r s}+\mathrm{f}_{6}^{r s}+\mathrm{f}_{8}^{r s}=529(\mathrm{pcu})
$$

In the example the traffic volume of each path on the map is shown in Fig .2. For the next several 15 minutes, we can calculate the traffic impedance and distribute the traffic volume using the proposed method, so the distribution traffic volume on the road will be adjusted once every 15 minutes, forming a dynamic traffic volume allocation process.

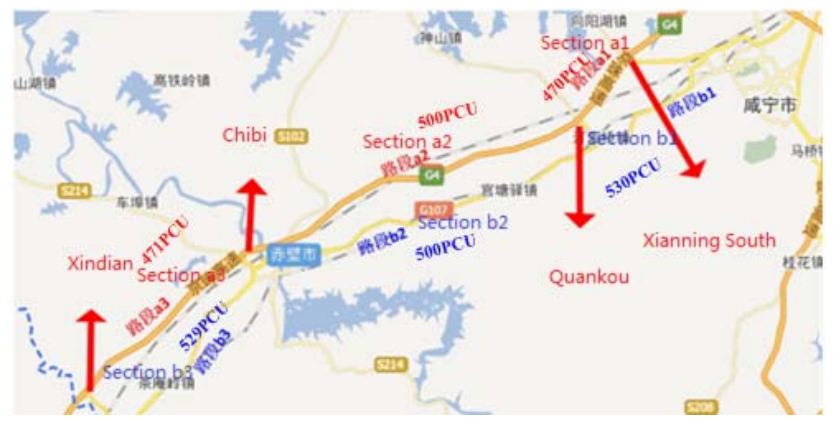

Figure 2. The distribution traffic volume of each path

\section{CONCLUSION}

Based on the traveler's subjective preference, we construct a new traffic impedance function. In addition to considering the characteristics of traffic flow itself, as well as the subjective choice of the traveler under the influence of multiple factors, and function parameters were determined by linear regression method. Assuming that the impedance was constant, we use the constructed function combined with the multiple path allocation method of
Logit model to analyze the allocation example. The result shows good applicability of impedance function.

\section{ACKNOWLEDGMENT}

This work is supported by the Opening Project of Key Laboratory of Road Safety Technologies, Ministry of Transport, P. R. China.

\section{REFERENCES}

[1] Liu An, Yang Peikun. "A study on the UE assignment model and its algorithms for Chinese mixed urban traffic networks," Journal of Highway and Transportation Research and Development, 1996, $9(3): 23$.

[2] Liu Ning, Zhao Shengchuan, He Nan. "Further study of impedance function based on BPR function", Journal of Wuhan University of Technology(Transportation Science

Engineering),2013,37(3):545-548,doi:10.3963/j.issn.20953844.2013.03.023.

[3] Ma Shou-feng, Long Yue. "A dynamic assignment model with arrival time constraint in the combination of traffic control and vehicles route guidance," Journal of Systems \& Management,2007,16(5):472-476.

[4] Lu Huapu, Yu Xinxin, Li Yue. "User equilibrium traffic assignment with morgenstern utility theory", Highway Engineering,2010,35(4):12-14.

[5] Wang Wenjing, Jing Ming, Liu Dongmei, Wang Jing. "Study on capacity limitation-multipath routing traffic allocation based on LOGIT model and BPR impedance function," Journal of Highway and Transportation Research and Development,2012,S1:8185,doi:10.3969/j.issn.1002-0268.2012.S1.015.

[6] Wang Yuanqing, Zhou Wei, LV Lianen. "Theory and application study of the road traffic impedance function," Journal of Highway and Transportation Research and Development,2004,21(9):8285,doi:10.3969/j.issn.1002-0268.2004.09.0082.04

[7] Zhang Yingying. "Study on integrated traffic impedance function by use of AHP method," Journal of Highway and Transportation Research and Development,2007,24(3):115117,doi:10.3969/j.issn.1002-0268.2007.03.0115.03

[8] Zha Weixiong, Wang Shibin. "Research on impedance function of unsaturated urban mixed traffic," Journal ofHighway and Transportation Research and Development,2010,27(9):100 104,doi:0.3969/j.issn.1002 -0268.2010.09.0100.05

[9] He Nan,Zhao Shengchuan. "Study on urban road impedance function model-a case study of dalian city," 2014,31(2):104108,doi:10.3969/j.issn.1002-0268.2014.02.018

[10] Li Qiang. "On clustering methods of traffic flow time series and application,” Beijing Jiaotong University, 2011. 